\title{
ONLINE SHOPPING AND BUYING BEHAVIOR OF COLLEGE STUDENTS IN KATHMANDU
}

\author{
Padam Bahadur Lama*
}

\begin{abstract}
This study examines the association and impact of online shopping on buying behavior of college students in Kathmandu. The delivery guarantee $(D G)$, product quality $(P Q)$,service information quality (SIQ), and website factor (WF) are independent variables. The dependent variable is buying behavior of college students (BBCS). The research is based on primary data collected from college students in Kathmandu. The cross-sectional data is mainly gathered from college students as a user of online shopping. Structured questionnaire of total 500distributed and received 115 (23 percent)useful data from respondents. The regression models are estimated for assessing the significance and impact of delivery guarantee, product quality, service information quality, and website factor on buying behavior of college students.
\end{abstract}

The study shows that delivery guarantee is positively associated with buying behavior of college students. It reveals that the higher the delivery guarantee, higher would-be buying behavior of college students. The product quality is positively related with buying behavior of students but found insignificant. However, the service information quality is positively related with buying behavior of college students. It shows that higher the service information quality, higher would be the buying behavior of college students. Similarly, the website factor is found positively associated with buying behavior of college students. It depicts that the supportive website factor increases the buying behavior of college students.

Keywords: Buying behavior of college students, delivery guarantee, product quality, service information quality, website factor, and online shopping.

\section{Introduction}

The emergence of online shopping has been used tremendously in the market for buying the product or services. The evolution of sophisticated technology is contributing aspect to flourishing online shopping behavior. Online shopping has generated more advantages as compared to the physical stores in the market as online shopping or buying process are more useful to save time, convenient and it does not require the client to stay in line and even not physically required the traveling. Online shopping is available most of the time and it's been useful as it is accessible all the time in every corner of the area. Further, online shopping is being more convenient as it provides sufficient information on products and services (Moshrefjavadi et al., 2012).

\footnotetext{
* Assistant Professor of Saraswati Multiple Campus (Management Faculty), Tribhuvan University, Nepal.
} 
Online shopping comprises buyers for exploring, choosing, buying, and conducting activities to process buying action to fulfill the desires of the buyers(Tham et al., 2019). Thus, the behavior of online shopping which is also known as online buying behavior and internet buying or shopping behavior represents the idea that it is the process of acquiring a service or product through the internet (Moshrefjavadi et al., 2012). Similarly, online shopping or buying refers to the procedures for procuring products and services online (Zuroni \& Goh, 2012). Further, development in infrastructure of communication and technological change led the students/buyers as the factor for influencing buying behavior as well as shows their association with shopping with online (Khare \& Rakesh, 2011). Moreover, the use of online shopping creates the space for the comparison and screening of alternative information which is a way to minimize information cost and fewer efforts for making a buying decision of goods and services. As the online shopping/buying process is associated with interacting through the computer system of websitebased services and not having a chance to observe the product or services but buying decision is made depending on the information being available on the website(Park \& Kim, 2003). On the other hand, as per the shopping orientation of buyers, the buying decision may differ in their behavioral aspect (Handa \& Gupta, 2014). However, the influencing factors in decision-making on their procurements havebeen perceived differently among consumers(Nittala, 2015).

Sinha and Kim (2012) conducted a study on factors affecting Indian consumers' online buying behavior and the result found that the inclined emphasis on product delivery has found significant which influences on the attitude of buyers while operating shopping through online.

Vijayasarathy and Jones (2005) held the study on print and internet catalog shopping: assessing attitudes and intentions which found that product value as a factor influenced attitudes and intentions to shop using print and internet catalogs. The characteristics or quality of product apart from distribution, transaction and communication via online does have a substantial impact on buying the product (Kiang \& Chi, 2001). The product quality was found to have a significant effect on consumer's site commitment (Park \& Kim, 2003).

Seock and Bailey (2008) conducted the study on the influence of college students' shopping orientations and gender differences on online information searches and purchase consisting of 1277 US college students and result revealed that buying orientation of participants were significantly associated with the search of product information and buys apparel items through online platform. The service information quality was found to have a significant effecton consumer's site commitment(Park \& Kim, 2003).

Muthupriya (2019)held a study and found the result that the significant association does not create on online buying with usability of the website. Clemes et al., (2014) conducted a research work on empirical analysis of online shopping adoption in Beijing, China comprising the sample from 435 respondents and found that the empirical analysis identifies website factors and others as major factors generating impact on consumers of China for embracing the shopping through online.

In the context of Nepal, Mainali et al., (2016)researched impulse buying behavior of college students in Kathmandu valley, the result found that there is a positive association between the impulsive buying behavior of students with media, self-esteem, impulsivity, anxiety, and social desirability and these effects are found moderately influencing. Joshi and Shrestha (2016) held a study on influencing factors on consumer buying behavior of smartphones and found that the 
main online buyers were aged between 21-25 and own Samsung followed by iPhone. Rawal (2021) conducted research on the level of consumer awareness among college students found that the aggregate awareness of buyers is found low regarding the labeling information of packaged products and management students are found more familiar compared with others. Rawal (2019) held a study on perception of consumer rights among the college students: a case of Tikapur Municipality found that recent attitudes of buyers in marketing practices concerning buyer's right protection is least supportive requiring deeper enhancement in it.

The discussion held above depicts that the output or result of researches is diversified and not having consistency among the various research works even in the field of online shopping and buying behavior of the customer. Further, only a few studies have been conducted in the Nepalese context comprising the area of online shopping and buying behavior of college students. Therefore, the study conducted here assesses the impact of online shopping on buying behavior of college students in Kathmandu. The objective of this study is to examine the impact of online shopping with variables such as delivery guarantee, product quality, service information quality, website factor on buying behavior of college students in Kathmandu.

The study has been organized in this way: section two demonstrates sample description, data, and methodology. Further, empirical results are comprised in section three. Finally, the conclusion and discussion part are encompassed in the final section.

\section{Methodology}

The research is conducted using primary data collecting from 115 college students as respondents comprising their buying behavior towards online shopping and data were especially accumulated from students of selected colleges in Kathmandu. The opinion of respondents was accumulated onthe delivery guarantee, product quality, service information quality,website factor, and buying behavior of college students. The study is based on cross-sectional data and adopted descriptive statistics, correlation, and regression analysis to analyze the research results.

\section{The Model}

The estimated model for this research study predicts that buying behavior of college students depends on the delivery guarantee, product quality, service information quality, and website factor.

The estimated model is developed:

$\mathrm{BBCS}=\alpha+\beta 1 \mathrm{DG}+\beta 2 \mathrm{PQ}+\beta 3 \mathrm{SIQ}+\beta 4 \mathrm{WF}+\mathrm{e}$

Where,

BBCS $=$ Buying Behavior of College Students

$\mathrm{DG}=$ Delivery Guarantee

$\mathrm{PQ}=$ Product Quality

$\mathrm{SIQ}=$ Service information quality

$\mathrm{WF}=$ Website factors 
Buying behavior of college students was measured with five points Likert scale as used by (Khare $\&$ Rakesh, 2011). The 5-point Likert scale in the study was used while collecting responses from respondent students indicating $(1=$ strongly disagree, $2=$ disagree, $3=$ undecided, $4=$ agree and $5=$ strongly agree). In the study, items comprise "I prefer to buy through the online platform", "I often think to buy goods and services from online" as sample items for the research, and other items wereused for the same. The reliability of the buying behavior of college students was measured by Cronbach's alpha $(\alpha=0.649)$.

The delivery guarantee was adopted in the study as an independent variable and measured along with a 5-point Likert scale as used by (Al-Jahwari et al., 2018). The item introduced with delivery guarantee was used to inquire respondents to show the position of their agreement or aspect of disagreement over the adopted statement under-delivery guarantee. The delivery guarantee integrated ( $1=$ strongly disagree to $5=$ strongly agree) comprising the items in the sample as "proper package and delivery of online shopping delivery found flexible and responsible", "product is received without any damage from online shopping" and so on. The reliability of the delivery guarantee was measured by Cronbach's alpha $(\alpha=0.647)$.

Product quality was undertaken in the research and adopted the 5-point Likert scale as used by (Al-Jahwari et al., 2018). The Likert point used in searching the opinion of respondents through product quality reflects the views of respondents demonstrating a situation of agreement and disagreement with the statement presented in the questionnaire as $(1=$ strongly disagree to $5=$ strongly agree). The items included in product quality to measure the opinion of respondents were like "product quality found assured during online shopping", "product's quality-related information was consistent with information collected from online" and so on. The reliability of the product quality was measured by Cronbach's alpha $(\alpha=0.720)$.

Service information quality was measured along with a 5-point Likert scale as adopted by (Park $\&$ Kim, 2003). The expression of views of respondents was measured showing $(1=$ strongly disagree to $5=$ strongly agree). Items for the study and examination of views of the respondents were like "online shopping site does provide up-to-date information regarding services", "online shopping site provides relevant and reliable service information", and so on. The reliability of the service information quality was measured by Cronbach's alpha $(\alpha=0.666)$.

Website factor was used as one part of the independent variable and measured with a 5-point Likert scale as used by (Katta \& Patro, 2017; Clemes et al., 2014). The expression of views of respondents was accumulated with $(1=$ strongly disagree to $5=$ strongly agree $)$. Views and opinion of respondents were gathered using items as "online shopping transaction is easy and accessible through the website", the website gives detailed information answering the queries of buyers" and so on. The reliability of the website factor was measured by Cronbach's alpha ( $\alpha=$ 0.672 ).

\section{Delivery Guarantee}

Delivery service is the process of connecting in a supply chain that deals directly with buyers (Ahn et al., 2004). The reliable and consistent delivery is an item of means objectives in online or electronic commerce meanwhile acquiring the product in time is a major objective (Keeney, 1999). 
$H_{1}$ : Delivery guarantee has a positive relationship with buying behavior of college students.

\section{Product Quality}

The product standard or quality perceived by the buyer can be defined as a process of judgment over entire goods and services including their service or product superiority along with its appreciation through its approached reasons relative to alternatives (Boisvert \& Burton, 2009). Product quality can further be defined as a means of the accurate workability or functionality of the product, consistency in between the quality specification of shopping online mart and actual quality of physical goods (Ahn et al., 2004).

$\mathrm{H}_{2}$ : product quality has a positive relationship with buying behavior of college students.

\section{Service Information Quality}

The service information quality can be defined as the process used to indicate the availability of multiple communication systems to obtain feedback from customers and settle it in time and contains the concept of supporting customers for the use of product effectively (Bhattacherjee, 2001).

$H_{3}:$ Service information quality has a positive relationship with buying behavior of college students.

\section{Website Factor}

Harrison-Walker (2002) stated that a website containing the images, color in the background, logos, shopping procedure, and fonts integrated intothe designing website isan essential foundation to expand the experiences of consumers. Clemes et al., (2014) defined websites as basically a storehouse of information in which websites are fundamentally stored houses of information that can assist buyers while searching for the information.

$H_{4}$ : Website factor has a positive relationship with buying behavior of college students.

\section{Buying Behavior}

The shopping or buying behavior is defined as a process of exploring and procuring goods and services through the use of the online internet (Varma \& Agarwal, 2014). 


\section{Results and Discussion}

\section{Descriptive Statistics}

\section{Table 1}

Profile of Respondent

\begin{tabular}{llcc}
\hline Demographic Variables & Characteristics & Frequency & Percent \\
\hline \multirow{4}{*}{ Age } & Below 20 & 62 & 53.9 \\
& $20-29$ & 49 & 42.6 \\
Gender & $30-39$ & 3 & 2.6 \\
Marital Status & 40 and above & 1 & 0.9 \\
& Female & 75 & 65.2 \\
& Male & 40 & 34.8 \\
Oarried & Single & 14 & 12.2 \\
Occupation & Business Person & 101 & 87.8 \\
& Government Employee & 1 & 0.9 \\
& Private Sector Employee & 3 & 2.6 \\
Frequency of online shopping & Student & 11 & 9.6 \\
& 10+2 Level & 99 & 86.1 \\
& Bachelor Level & 6 & 5.2 \\
& Master and above & 91 & 79.1 \\
& Daily & 16 & 13.9 \\
& Every week & 2 & 1.7 \\
& Never & 6 & 5.2 \\
& Once in a month & 14 & 12.2 \\
& Once in a year & 31 & 27.0 \\
Online buying product & Once in six months & 32 & 27.8 \\
& Below Rs. 5000 & 28 & 24.3 \\
Monthly Income & Rs. 5000 - Rs. 10,000 & 53 & 55.2 \\
& Rs. 10,001 - Rs. 20,000 & 14 & 12.6 \\
& Rs. 20001 - Rs. 30,000 & 14 & 12.6 \\
& Rs. 30,001 - Rs. 40,000 & 10 & 9.2 \\
& Rs. 40,001 - Rs. 50,000 & 6 & 5.7 \\
& Food/beverage & 5 & 4.6 \\
& Clothing/Accessory/Shoes & 70 & 27.8 \\
& Computer/Electronics/Software & 18 & 64.8 \\
& Book/DVD/CD & 11 & 16.7 \\
& Others & 24 & 22.2 \\
& Daraz & 67 & 62.6
\end{tabular}




\begin{tabular}{llcc} 
& Hamrobazar & 16 & 15 \\
Use of the website for online shopping & SastoDeal & 6 & 5.6 \\
& Foodmandu & 23 & 21.5 \\
& SmartDoko & 0 & 0 \\
& Metrotarkari & 0 & 0 \\
Total & Others & 45 & 42.1 \\
& & $\mathbf{1 1 5}$ & $\mathbf{1 0 0 . 0}$ \\
\hline
\end{tabular}

In above table 1, the data distribution for the study was 500 college students in the selected colleges in Kathmandu. The students as respondents of the study who submitted a questionnaire to the researchers were 115 ( 23 percent). The majority of respondents were from the below 20 years of age group ( 54 percent) and above 40 years of age group respondents were $(0.9$ percent). The female participants were $(65.2$ percent $)$ and male respondents were $(34.8$ percent). The majority of respondents were single (87.8 percent) and married respondents were (12.2 percent). Respondents holding bachelor level were major respondents (79.1 percent) and $10+2$ level of respondents were $(5.2$ percent). In the frequency of online shopping among the respondents as a majority of respondents were once in a year (27.8 percent) and never items were (12.2 percent). The respondents generating monthly income below Rs 5000 is (55.2 percent) and least income group among the respondents is income level between Rs. 40,001 - Rs. 50,000 (4.6 percent). The online buying product status of respondents occupied multiple options in the selection and even a single respondent found multiple options in the selection of this item. Among the respondents, the majority preferred to buy Clothing/Accessories/Shoes (64.8 percent) and Book/DVD/CD preferred respondents were (10.2 percent). Finally, the majority of respondents used hamrobazar (62.6 percent) and Smartdoko and Metrotarkari found no response ( 0 percent).

\section{Correlation Analysis}

The correlation analysis has been used to assess the association between the variables. In this aspect, the Pearson's correlation coefficients have been computed and the result on the same is shown in Table 2. Buying behavior of college students is used as a dependent variable in the study and independent variables adopted for the study are delivery guarantee (DG), product quality $(\mathrm{PQ})$, service information quality (SIQ), and website factors (WF).

\section{Table 2}

Pearson's Correlation Matrix

\begin{tabular}{lccccccc}
\hline Variables & Mean & Std. Deviation & PQ & DG & SIQ & WF & BBCS \\
\hline PQ & 3.3726 & 0.59158 & 1.000 & & & & \\
DG & 3.5426 & 0.50871 & $.329^{* *}$ & 1.000 & & & \\
SIQ & 3.3913 & 0.56964 & $.304^{* *}$ & $.523^{* *}$ & 1.000 & & \\
WF & 3.8313 & 0.45775 & $.202^{*}$ & $.273^{* *}$ & $.317^{* *}$ & 1.000 & \\
BBCS & 3.4383 & 0.59877 & 0.161 & $.389^{* *}$ & $.329^{* *}$ & $.309^{* *}$ & 1.000 \\
\hline
\end{tabular}

Table number 2 shows the Pearson's correlation based on the data collected from respondents. The product quality is positively related with buying behavior of college students. Further, the delivery guarantee is positively associated with buying behavior of college students. It depicts that 
better the delivery guarantees higher would-be buying behavior of college students. Further, service information quality is positively associated with buying behavior of college students. It shows that better service information quality leads to the higher buying behavior of college students. Finally, the website factor is positively related with buying behavior of college students. It shows that the supportive website factor leads to an increase in the buying behavior of college students in online shopping.

\section{Regression Analysis}

The regression analysis has been computed after computing the Pearson's correlation coefficients and the output of the regression computation is presented in Table 3. The regression result is based on the delivery guarantee (DG), product quality (PQ), service information quality (SIQ), and website factors (WF) on buying behavior of college students in the selected college students in Kathmandu. The estimated regression output from these dependent and independent variables is computed consisting of the 115 observations of respondents witha linear regression model. The estimated model for the regression is BBCS $=\alpha+\beta_{1} \mathrm{DG}+\beta_{2} \mathrm{PQ}+\beta_{3}$ SIQ $+\beta_{4} \mathrm{WF}+\mathrm{e}$ where the dependent variable is buying behavior of college students (BBCS) and variables used as independent variables are delivery guarantee (DG), product quality $(\mathrm{PQ})$, service information quality (SIQ) and website factors (WF).

Table 3

Regression Analysis

\begin{tabular}{|c|c|c|c|c|c|c|c|}
\hline Regression & (1) & (2) & (3) & (4) & (5) & \multicolumn{2}{|c|}{$\begin{array}{c}\text { Collinearity } \\
\text { Statistics } \\
\text { ToleranceVIF }\end{array}$} \\
\hline Intercept & $\begin{array}{l}2.888^{* * * *} \\
(8.98)\end{array}$ & $\begin{array}{l}1.818^{* * *} \\
(4.98)\end{array}$ & $\begin{array}{l}2.265^{* * *} \\
(7.05)\end{array}$ & $\begin{array}{l}1.889^{* * *} \\
(4.18)\end{array}$ & $\begin{array}{l}1.367^{* * *} \\
(4.09)\end{array}$ & & \\
\hline PQ & $\begin{array}{l}0.163 \\
(1.74)\end{array}$ & & & & & .859 & 1.165 \\
\hline DG & & $\begin{array}{l}0.457^{* * * *} \\
(4.48)\end{array}$ & & & & .667 & 1.499 \\
\hline SIQ & & & $\begin{array}{l}0.346^{* * *} \\
(3.71)\end{array}$ & & & .672 & 1.488 \\
\hline WF & & & & $\begin{array}{l}0.404 * * * \\
(3.46)\end{array}$ & & .721 & 1.386 \\
\hline Adjusted R2 & 0.0174 & 0.1435 & 0.1004 & 0.0876 & 0.2514 & & \\
\hline SEE & 0.594 & 0.554 & 0.568 & 0.572 & 0.518 & & \\
\hline
\end{tabular}




\begin{tabular}{|c|c|c|c|c|c|}
\hline F-Value & 3.016 & 20.09 & 13.73 & 11.95 & 39.29 \\
\hline t statistics & in pare & & & & \\
\hline$* \mathrm{p}<0.05, * *$ & $\mathrm{p}<0.0$ & $\mathrm{p}<0.0$ & & & \\
\hline
\end{tabular}

Table 3 depicts the regression result and the beta coefficients for product quality is positive with buying behavior of college students but it is insignificant. Moreover, the regression result along with the beta coefficient of delivery guarantee is positive and significant with buying behavior of college students. It indicates that delivery guarantee has a positive impact on buying behavior of college students advocating that better the delivery guarantees higher would-be buying behavior of college students. This result is consistent with (Sinha and Kim, 2012). Similarly, the beta coefficient of service information quality is positive and significant with buying behavior of college students depicting that service information quality has a positive impact on buying behavior of college students. This result is consistent with (Park \& Kim, 2003). In the same way, the beta coefficient of the website factor is positive with buying behavior of college students depicting the significance. It reflects that the website factor has a positive impact on buying behavior of college students. Finally, the VIF value shown in the same table indicates that there is no problem withmulticollinearity.

\section{Summary and Conclusion}

The study assesses the association and impact of online shopping on buying behavior of college students comprising the students of Kathmandu valley. The study was fundamentally conducted using primary data with 115 observations. Especially, this study pursued and comprised the context of online shopping and buying behavior of college students through developing questionnaires in the study.

Output generated through the study shows that the product quality is positively associated with buying behavior of college students but found insignificant. However, the delivery guarantee is positively associated with buying behavior of college students which depicts that assurance of delivery guarantee leads to the higher buying behavior of college students. Similarly, service information quality and website factors are positively related with buying behavior of college students depicting that better service information quality and website factor that lead to increase the buying behavior of college students. Beta coefficient for the delivery guarantee, service information quality, and website factor are significant and positive with buying behavior of college students. However, the beta coefficient of product quality is found insignificant in the study.

\section{References}

Ahn, T., Ryu, S., \& Han, I. (2004). The impact of the online and offline features on the user acceptance of Internet shopping malls. Electronic Commerce Research and Applications, 3(4), 405-420. https://doi.org/10.1016/j.elerap.2004.05.001

Al-Jahwari, N. S., Khan, M. F. R., Al Kalbani, G. K., \& Al Khansouri, S. S. (2018). Factors 
influencing customer satisfaction of online shopping in Oman - Youth perspective. Humanities and Social Sciences Reviews, 6(2), 64-73. https://doi.org/10.18510/hssr.2018.628

Bhattacherjee, A. (2001). An empirical analysis of the antecedents of electronic commerce service continuance. Decision Support Systems, 32(2), 201-214. https://doi.org/10.1016/S01679236(01)00111-7

Boisvert, J., \& Burton, S. (2009). The impact of perceived innovativeness, branding strategy and parent brand salience on the reciprocal transfer of core associations. International Journal of Business Excellence, 2(3-4), 346-359. https://doi.org/10.1504/IJBEX.2009.024452

Clemes, M. D., Gan, C., \& Zhang, J. (2014). An empirical analysis of online shopping adoption in Beijing, China. Journal of Retailing and Consumer Services, 21(3), 364-375. https://doi.org/10.1016/j.jretconser.2013.08.003

Handa, M., \& Gupta, N. (2014). A Study of the Relationship between Shopping Orientation and Online Shopping Behavior among Indian Youth. Journal of Internet Commerce, 13(1), 22 44. https://doi.org/10.1080/15332861.2014.918437

Harrison-Walker, L. J. (2002). If You Build It, Will They Come? Barriers to International eMarketing. Journal of Marketing Theory and Practice, 10(2), 12-21. https://doi.org/10.1080/10696679.2002.11501912

Joshi, A., \& Shrestha, S. (2016). Influcing Factors On Consumer Buying Behaviour Of Smart Phones. Bachelor of Business Administration (BBA), 68.

Katta, R. M. R., \& Patro, C. S. (2017). Online Shopping Behavior. International Journal of Sociotechnology and Knowledge Development, 8(4), 21-36. https://doi.org/10.4018/ijskd.2016100102

Keeney, R. L. (1999). Value of internet commerce to the customer. Management Science, 45(4), 533-542. https://doi.org/10.1287/mnsc.45.4.533

Khare, A., \& Rakesh, S. (2011). Antecedents of Online Shopping Behavior in India: An Examination. Journal of Internet Commerce, 10(4), 227-244. https://doi.org/10.1080/15332861.2011.622691

Kiang, M. Y., \& Chi, R. T. (2001). A Framework for Analyzing the Potential Benefits of Internet Marketing. Journal of Electronic Commerce Research, 2(4), 157-163.

Mainali, Y., Shakya, A., \& Pandey, P. (2016). Impulse Buying Behavior of College Student in Kathmandu Valley. Advances in Economics and ..., 3(6), 608-611. https://www.krishisanskriti.org/vol_image/15Dec201606125008 Yogesh Mainali 608-611.pdf

Moshrefjavadi, M. H., Rezaie Dolatabadi, H., Nourbakhsh, M., Poursaeedi, A., \& Asadollahi, A. (2012). An Analysis of Factors Affecting on Online Shopping Behavior of Consumers. International Journal of Marketing Studies, 4(5). https://doi.org/10.5539/ijms.v4n5p81 
Muthupriya, A. (2019). Online Shopping Attitude Among the Youth: A Study on Alagappa University Students in Karaikudi, Sivaganga District. Shanlax International Journal of Management, 7(1), 43-47. https://doi.org/10.34293/management.v7i1.450

Nittala, R. (2015). Factors Influencing Online Shopping Behavior of Urban Consumers in India. International Journal of Online Marketing, 5(1), 38-50. https://doi.org/10.4018/ijom.2015010103

Park, C. H., \& Kim, Y. G. (2003). Identifying key factors affecting consumer purchase behavior in an online shopping context. International Journal of Retail \& Distribution Management, 31(1), 16-29. https://doi.org/10.1108/09590550310457818

Rawal, Dhabindra. (2019). Perception of Consumer Rights among the College Students: A Case of Tikapur Municipality. Contemporary Research: An Interdisciplinary Academic Journal, 3(1), 25-32. https://doi.org/10.3126/craiaj.v3i1.27486

Rawal, Dhavindra. (2021). Level of consumer awareness among the college students. 2, 10-18.

Seock, Y. K., \& Bailey, L. R. (2008). The influence of college students' shopping orientations and gender differences on online information searches and purchase behaviours International Journal of Consumer Studies, 32(2), 113-121. https://doi.org/10.1111/j.14706431.2007.00647.x

Sinha, J., \& Kim, J. (2012). Factors affecting Indian consumers' online buying behaviour. Innovative Marketing, 8(2), 46-57.

Tham, K. W., Dastane, O., Johari, Z., \& Ismail, N. B. (2019). Perceived risk factors affecting consumers' online shopping behaviour. Journal of Asian Finance, Economics and Business, 6(4), 246-260. https://doi.org/10.13106/jafeb.2019.vol6.no4.246

Varma, I. G., \& Agarwal, M. R. (2014). Online Buying Behaviour of Homemakers in Western Suburbs of Mumbai and Social Media Influence. IOSR Journal of Business and Management, 16(8), 42-65. https://doi.org/10.9790/487x-16814265

Vijayasarathy, L. R., \& Jones, J. M. (2005). Emerald Article: Print and Internet catalog shopping: assessing attitudes and intentions Print and Internet catalog shopping: assessing attitudes and intentions. 10(3), 191-202.

Zuroni, M. J., \& Goh, H. L. (2012). Factors Influencing Consumers' Attitude Towards ECommerce Purchases Through Online Shopping. International Journal of Humanities and Social Science, 2(4), 223-230. 